POLÍTICA FISCAL E DÍVIDA PÚBLICA

\title{
Efeitos da eliminação da dívida externa líquida
}

\author{
Jedson César de Oliveira* \\ Fernando Motta
}

RESUMO - Por muitos anos verificou-se a ocorrência de déficits na conta de transações correntes do Brasil, o que obrigava o país a se financiar por meio da entrada de capitais, gerando um acúmulo de sua dívida externa. Recentemente, o país logrou uma condição de credor externo líquido, devido ao volume de reserva internacional em moeda estrangeira superior ao volume da dívida externa; esse resultado tem importantes conseqüências em termos de política econômica interna. Ainda que financiamento externo tenha sido importante em algumas fases da economia brasileira, a dependência gerada em função deste capital traz desagradáveis situações que podem comprometer a estabilidade macroeconômica de um país em razão da instabilidade dos fluxos de capitais e a facilidade com que distúrbios em determinados países se propagam para a economia interna, o que compromete a liberdade na condução das políticas econômicas. A mudança do país da posição de devedor para credor externo líquido, mesmo com um elevado custo fiscal, traz consigo melhores condições para se lidar com as crises externas que, atualmente, têm como fonte o sistema financeiro americano.

Palavras-chave: Dívida Externa. Dívida Interna. Reservas em moeda estrangeira.

Não é de hoje que o tema da dívida externa tornou-se ponto chave nas discussões de política econômica do país. No final da década de 70 as autoridades econômicas norteamericanas passaram a adotar uma política monetária restritiva, devido à forte desvalorização do dólar que vinha se propagando desde 1973 com a implantação do sistema de taxas de câmbio flutuantes. Aliado aos elevados déficits públicos que se mantinham naquele país, observou-se um aumento significativo nas suas taxas de juros, tornando-o grande absorvedor de liquidez internacional. Neste cenário, os credores dos países em desenvolvimento endividados, caso do Brasil, restringiram a obtenção de recursos externos.

O resultado dessa política restritiva norte-americana para o Brasil se refletiu em negociações com o FMI, já em 1982, na tentativa de buscar empréstimos compensatórios e aval para a negociação da dívida externa, como forma de evitar a ampliação da crise cambial.

\footnotetext{
* Mestre em Desenvolvimento Econômico pela Universidade Federal do Paraná (UFPR) e Professor da Estação Business School-IBMEC. Endereço eletrônico: jedson@estacaopr.com.br.

** Doutorando em Desenvolvimento Econômico pela Universidade Federal do Paraná (UFPR). Endereço eletrônico: fmottabr@yahoo.com.br.
} 
Os acordos com o FMI, no início da década de 80, forçaram o país a gerar superávits comerciais de modo a compensar os déficits na balança de serviços e permitir o pagamento dos juros da dívida externa.

O gráfico 1 ilustra o comportamento da dívida externa brasileira a partir de 1970. Verifica-se um crescente aumento ao longo do período em função da necessidade de recursos para financiar o notável crescimento econômico brasileiro nessa década.

GRÁFICO 1 - DÍVIDA EXTERNA DO BRASIL (US\$ BILHÕES) - 1970 - 2007

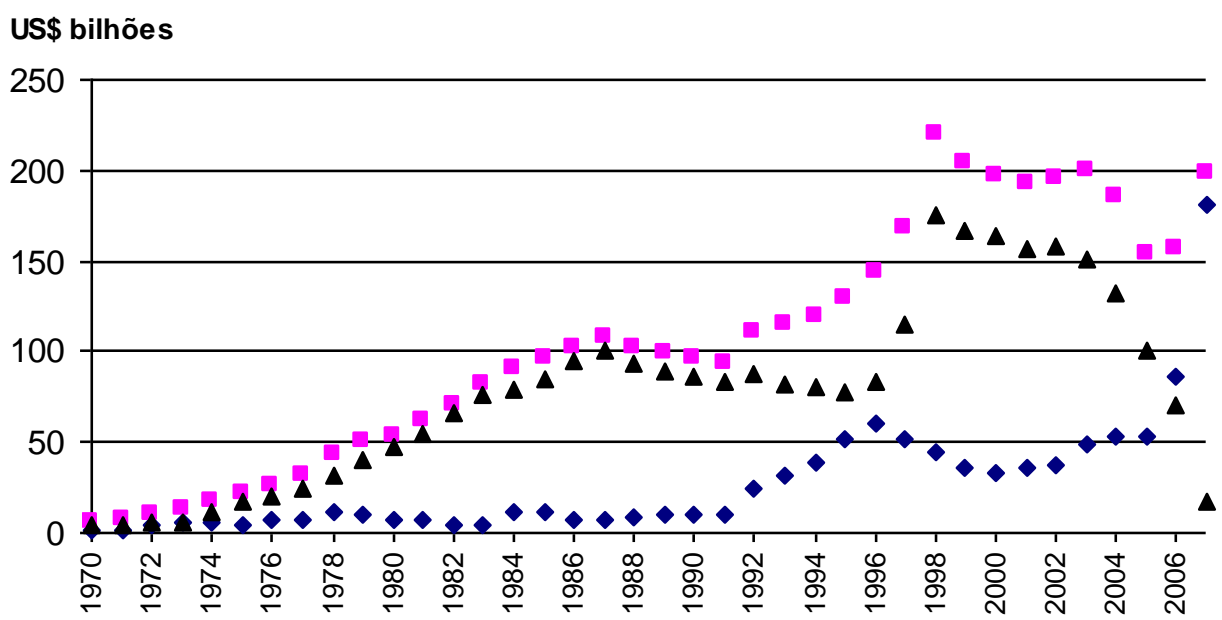

- Reservas • Dívida Externa $\Delta$ Dívida Externa líquida

FONTE: Banco Central do Brasil.

Os dados do gráfico mostram a tendência de queda da dívida externa líquida desde 2003. Esse desempenho positivo pode ser associado às reformas institucionais - econômicas que vêm sendo implementadas desde a década de 80 .

A economia brasileira, durante o período que compreende o início da década de 80 até os dias recentes, permite identificar algumas peculiaridades acerca do processo de desenvolvimento econômico.

Até o final da década de 70 o Brasil apresentava três restrições no que diz respeito à qualidade do seu desenvolvimento econômico: i) choques vivenciados na economia internacional afetavam diversos países, inclusive o Brasil; ii) políticas fundamentadas em bases antidemocráticas; e iii) desequilíbrio macroeconômico expresso pelas elevadas taxas de inflação.

Assim, o dueto institucional-econômico brasileiro no final da década de setenta apontava para um perfil de desenvolvimento orientado sob bases insustentáveis. A 
sustentação de qualquer processo de desenvolvimento deve ser guiada a partir de fundamentos institucionais e econômicos que se reflitam em equilíbrio macroeconômico, de modo que a causalidade que existe entre essas variáveis sinaliza a etapa de consecução desse processo de desenvolvimento.

O período de redemocratização no país que caracterizou a década de 80 contrasta com os aspectos econômicos, sobretudo com relação ao descontrole inflacionário. $\mathrm{Na}$ fase seguinte, a década de 90, junto com o processo de consolidação democrática, o país experimenta uma nova etapa de consecução do seu desenvolvimento, o controle da inflação com o advento do Plano Real. A tirar dos choques econômicos que fez ameaçar a busca pelo equilíbrio macroeconômico na segunda metade da década de 90 , o país inicia o novo milênio sob o enfoque de consolidação das bases econômicas promovidas desde a década de 80 .

Todavia, os resultados benéficos dessas reformas, que se refletem numa postura fiscal de credibilidade e possibilita o advento de capitais externos, criando um colchão amortecedor para o país enfrentar as crises externas, pode se refletir em possíveis prejuízos para os resultados da política econômica no Brasil.

O elevado nível de reservas que vem se verificando desde 2004 abre espaço para questionar o custo das esterilizações sobre variáveis importantes como a inflação e a dívida interna. As operações de esterilização ocorrem quando há uma venda de títulos públicos para diminuir a oferta de moeda encadeada pelo influxo de capitais, evitando uma queda na taxa de juros e, por conseqüência, um maior estímulo à demanda agregada, o que se reflete numa maior pressão sobre a taxa de inflação.

É importante destacar que os resultados dessas operações de esterilização, mesmo que necessárias numa política monetária do tipo metas de inflação podem dar origem a um distúrbio que pode comprometer a conduta fiscal do país.

Como todo aumento de capital externo eleva o passivo externo do país, por conseqüência ocorrerá uma ampliação do endividamento interno em virtude das operações de esterilização comentadas anteriormente. Assim a condição de credor externo líquido pode se refletir num deletério cenário para a situação fiscal do Brasil.

Segundo cálculos de analistas do próprio governo, o custo de ampliação das reservas cambiais, levando-se em conta o diferencial de taxa de juros interna e externa e a valorização do real frente ao dólar, alcançou em 2007 a casa dos R \$ 51 bilhões. O fato é que, ao acumular maciçamente reservas em 2007 - quando o Banco Central comprou liquidamente US\$ 78,59 bilhões - houve injeção de $\mathrm{R} \$ 155$ bilhões em reais na economia e colocação de papéis da 
dívida pública para enxugar essa liquidez. Em termos relativos, estima-se que o custo fiscal apenas da injeção da moeda nacional tenha sido da ordem de $0,8 \%$ do PIB. Além disso, a valorização da taxa de câmbio teve um custo fiscal de 1,1\% do PIB, o que contribuiu para um custo fiscal total de $1,9 \%$ do PIB.

O efeito negativo do fim do endividamento externo líquido, no entanto, foi a elevação do nível de endividamento interno, em reais. Apesar da dívida líquida do setor público ter caído de 44,7\% do PIB em 2006 para 42,8\% em 2007, a dívida interna líquida cresceu de 47,4\% do PIB para 51,9\% do PIB e a dívida interna não monetária (excluída da base monetária) passou de $42,3 \%$ do PIB para 46,4\% do PIB no período. Ou seja, do ponto de vista do endividamento, houve uma troca de dívida em dólar mais barata por dívida em reais considerada mais cara.

A compra de moeda estrangeira para se proteger dos períodos de crise externa tem um custo mensurável que são os juros nominais pagos sobre o volume emitido de títulos para enxugar a liquidez gerada na compra de dólares, no entanto, os benefícios não podem ser medidos, pois são mais qualitativos.

No caso específico de elevação das reservas em moeda estrangeira pode-se dizer que há uma forte percepção de que nos momentos de crise externa, possuir US\$190 bilhões em reservas com um regime de câmbio flutuante que absorva choques é uma grande vantagem, pois reduz fortemente a vulnerabilidade dos mercados financeiros internacionais, bem como possibilita o pagamento de menores prêmios de riscos nos financiamentos tomados no exterior tanto pelo Tesouro Nacional quanto pelas empresas.

Levando-se em consideração que o atual patamar em que as reservas chegaram e o alto custo fiscal que essa decisão implica e, além disso, considerando que os benefícios a partir de agora são quase nulos, surge a dúvida se já não seria o momento de interromper o processo de acumulação que começou em 2004. Cada dólar a mais, quando já se tem US\$190 bilhões, adiciona menos proteção do país a crises do que adicionava quando as reservas eram de US\$ 17 bilhões, no entanto, o custo continua sendo elevado.

No entanto, de acordo com o Banco Central, mesmo com esse volume de reservas, a crise externa causada pelos "subprimes" americanos elevou o risco-país e provocou maiores incertezas quanto a um possível processo recessivo mundial. Assim, o efeito líquido de continuar acumulando reservas ainda seria positivo.

Contudo, vale a pena observar que há uma alternativa que permite continuar acumulando reservas sem que haja um impacto tão oneroso aos cofres públicos, qual seja: 52 
reduzir a taxa de juros Selic. Essa medida teria efeitos positivos tanto no sentido de evitar a continuidade da valorização do câmbio quanto na redução do elevado diferencial de juros interno e externo.

Considerando que o perfil do Banco Central tem sido fortemente conservador, a optar pela alternativa de reduzir os juros para evitar que o Real continue se apreciando frente às principais moedas do mundo e, ao mesmo tempo, continue reduzindo o déficit fiscal desde 2005 é quase uma heresia, já que o Banco Central brasileiro é um dos poucos atores do setor financeiro que enxerga uma expansão da inflação baseada no aumento da demanda.

O Brasil parece não aprender com as lições do passado, pois em inúmeras oportunidades - principalmente no passado recente - poderia ter observado que tanto a economia interna quanto a externa mundial tem sido mais afetadas por choques de oferta, tais como o petróleo, que tem batido sucessivos recordes de preços e as commodities agrícolas, como minério de ferro, soja e milho, do que por crescimento desordenado da demanda. Isso demonstra que o instrumento adotado para combater a inflação acaba prejudicando a economia, visto que o mais apropriado seria recorrer a instrumentos que impulsionem a expansão acelerada da oferta de bens e serviços. Ou seja, o Banco Central brasileiro tem utilizado o remédio errado e em dose elevada.

Dentro da abordagem explicitada anteriormente podem ser citadas, entre outras medidas, a redução das barreiras tarifárias às importações dentro de um contexto em que ocorra uma ampla negociação, como forma de contrapartida, para ampliação e/ou abertura de outros mercados internacionais que fazem alguma restrição aos nossos produtos. Isso contribuiria enormemente para a ampliação da oferta de bens e serviços no mercado interno e permitiria a continuidade do processo de crescimento no país com estabilidade de preços, já que, há quase três décadas, o Brasil não apresenta taxas de expansão econômica compatíveis com as necessidades de um país repleto de desigualdades e carências nas mais diversas áreas, tais como infra-estrutura e educação.

Outra medida que poderia ser tomada no sentido de permitir a adequação do ritmo de crescimento da oferta às necessidades da economia é a redução ou estabilização das despesas correntes como proporção do PIB, ou seja, o governo permite que os gastos públicos cresçam em termos nominais, porém eles devem ser inferiores ao ritmo de crescimento do PIB. Essa medida, considerada gradual, teria um duplo impacto, pois além de elevar a capacidade de investimentos do governo tão reprimidos nos últimos anos, possibilita que a demanda cresça em ritmo compatível com o crescimento da oferta de bens. 
Em suma, pode-se dizer que os efeitos da eliminação da dívida externa líquida são positivos, porém eles serão pequenos se novas medidas de âmbito interno não se somarem às corretas medidas tomadas em relação ao setor externo. A constatação de que a economia brasileira continua presa ao chamado processo "stop and Go", onde o crescimento se dá através de paradas e arrancadas, nos leva a concluir que há muito a ser feito. O setor externo permitiu que a economia interna superasse alguns obstáculos, principalmente os referentes às fugas de capital externo em momentos de crise, no entanto, sem a contrapartida interna o país continuará apresentando baixo crescimento econômico e inflação em descompasso.

Como de costume o Brasil continua apresentando um comportamento diferente dos demais países emergentes, já que a maioria deles tem tirado proveito do momento favorável na economia internacional e nós ainda crescemos muito pouco. O reconhecimento de que avanços foram feitos é importante para o desenvolvimento socioeconômico, porém ele não deve coadunar com a idéia de que "nunca na história desse país foi feito tanto", pois num mundo altamente dinâmico não há espaço para acomodações sob pena de continuarmos eternamente mantendo o rótulo de país do futuro.

\section{REFERÊNCIAS}

SISTEMA GERENCIADOR DE SÉRIES TEMPORAIS. Brasília: Banco Central do Brasil, 1970- 2007. Disponível em: https://www3.bcb.gov.br/sgspub/localizarseries/localizarSeri es.d o?method=preparar'TelaLocalizarSeries. Acesso em: 22/03/2008. 